\title{
GPS surveys in the foreland-foredeep tectonic system of Southeastern Sicily: first results
}

\author{
Alessandro Bonforte $\left({ }^{1}\right)$, Marco Anzidei $\left({ }^{2}\right)$, Giuseppe Puglisi $\left({ }^{3}\right)$, Mario Mattia $\left({ }^{3}\right)$, Orazio Campisi $\left({ }^{3}\right)$, \\ Giuseppe Casula $\left({ }^{2}\right)$, Alessandro Galvani $\left({ }^{2}\right)$, Arianna Pesci $\left({ }^{2}\right)$, Biagio Puglisi $\left({ }^{3}\right)$, \\ Stefano Gresta $\left({ }^{1}\right)$ and Paolo Baldi $\left({ }^{4}\right)$ \\ (1) Dipartimento di Scienze Geologiche, Sezione di Geologia e Geofisica, Università di Catania, Italy \\ ${ }^{(2)}$ Istituto Nazionale di Geofisica e Vulcanologia, Centro Nazionale Terremoti, Roma, Italy \\ $\left.{ }^{3}\right)$ Istituto Nazionale di Geofisica e Vulcanologia, Sezione di Catania, Italy \\ ( $\left.{ }^{4}\right)$ Dipartimento di Fisica, Settore Geofisica, Università di Bologna, Italy
}

\begin{abstract}
The Hyblean plateau (Southeastern Sicily) is characterised by three main tectonic structural trends: the first, NNW-SSE striking, runs on the easternmost part of the plateau and is linked to the Hyblean-Maltese fault system; the second runs along the western part of the plateau with a NNE-SSW direction and is characterised by a sinistral strike slip motion, like the Scicli fault; the third ENE-WSW striking, characterises the northernmost part of the area, including the Scordia-Lentini graben. We analysed GPS data collected in a dense network located in the northern area of the Hyblean plateau during 1998 and 2000, between the towns of Catania and Syracuse. Data from Noto, Matera and Cagliari IGS stations, were included in the processing to connect this network to the International Terrestrial Reference Frame (ITRF). The comparison between 1998 and 2000 data sets shows an average northward motion of the GPS stations located south of the Gela-Catania foredeep. Site velocities decrease from south to north and show a weak internal deformation of the northernmost part of the Hyblean plateau.
\end{abstract}

Key words ground deformations - GPS - regional tectonics - Hyblean plateau

\section{Introduction}

The main geological structures of Eastern Sicily (fig. 1) are represented by: i) the crystalline units of the Calabrian arc, which belong to the innermost unit of the chain; ii) the Maghrebian

Mailing address: Dr. Marco Anzidei, Istituto Nazionale di Geofisica e Vulcanologia, Centro Nazionale Terremoti, Via di Vigna Murata 605, 00143 Roma, Italy; e-mail: anzidei@ingv.it arc, which is a fold/thrust belt built up during Neogene as an effect of the consumption of different paleogeographic elements of the African and Apulian margins; iii) the Catania-Gela foredeep, running roughly $\mathrm{NE}$ to $\mathrm{SW}$; iv) the Hyblean plateau which represents the relatively undeformed foreland of the collision zone (Ben Avraham et al., 1990).

The Hyblean plateau belongs to the northernmost part of the Pelagian block which extends southward to the Malta islands (Ben Avraham et al., 1990). The plateau is bounded eastward by the NNW-SSE Hyblean-Maltese escarpment, one of the largest fault systems of the Mediterranean basin which separates the inland thick continental crust from the Ionian mesozoic oceanic crust underthrusting the Calabrian arc 


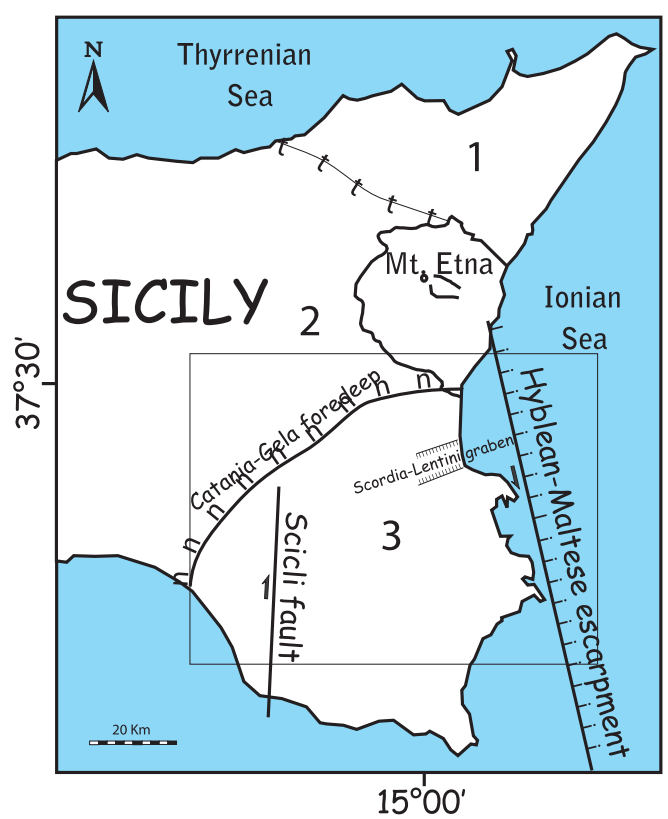

Fig. 1. Sketch of the structural setting of Eastern Sicily. $1=$ Crystalline units of the Calabrian arc; $2=$ units of the Maghrebian arc; $3=$ Hyblean plateau. The box indicates the spatial distribution of the GPS network described in this paper.

(Ben Avraham et al., 1995). On the western side, the Hyblean plateau is bounded by the NNESSW striking Scicli fault, which separates it from the foredeep, filled by the Gela nappe (i.e. the buried outermost thrust of the chain) through the Vittoria plain (Grasso et al., 2000). These two main structures isolate a block of the continental African foreland which resists thrusting/ subduction beneath the Maghrebian chain due to its high buoyancy (Ben Avraham and Grasso, 1991; Ben-Avraham et al., 1995). Along the Ionian margin a dense fault pattern form onshore a horst and graben sequence, oblique with respect to the Hybleo-Maltese escarpment, while the northern edge of the Hyblean plateau facing the northern foredeep areas is down faulted by NE-SW trending normal faults, forming structures as the Scordia-Lentini graben (Adam et al., 2000).
This complex structural setting plays an important role in the recent seismic activity of the area, characterised by major earthquakes along the western, northern and eastern boundaries of the Hyblean plateau. In particular, seismicity is characterised by lower magnitudes $(M<5)$ on the western side of the Hyblean plateau with respect to its northern $(M \approx 6)$ and eastern $(M \approx 7)$ areas, where destructive earthquakes occurred in 1169 and 1693. It is worth noting that the latter was proceeded by a strong foreshock of $M \approx 6$ which likely occurred along the same seismogenetic structure that produced an earthquake of $M \approx 6.5$ in 1542, identified as the southern fault of the Scordia-Lentini graben (Azzaro and Barbano, 2000). More recently, on December 13, 1990 the area was struck by a $M_{L}=5.4$ seismic event occurring offshore from the town of Augusta, which produced widespread damage between Syracuse and Catania. Although this is the only earthquake for which instrumental data are available, the seismogenic structure cannot clearly be identified due to the ambiguous fault plane solutions (Amato et al., 1995; Giardini et al., 1995). Azzaro and Barbano (2000) suggested an E-W striking right lateral fault, located east of the Scordia-Lentini graben, as the most probable source for this earthquake.

After this last earthquake, the area did not display important seismicity, except two weak seismic swarms between November 1999 and January 2000 (Scarfî et al., 2001).

In the frame of this complex tectonic setting, a preliminary ground deformation study was carried out along the Istituto Geografico Militare Italiano (IGMI) levelling route, measured several times since 1970 (Mulargia et al., 1991). In 1991, just after the 1990 earthquake, a geodetic monitoring program started with the aim of estimating the present day deformation of this area. One of the goals was to evaluate the relative kinematics of the tectonic structures of the Hyblean area, such as the Scordia-Lentini graben. The latter was invoked as a causative structure in the historical earthquakes affecting this area (Azzaro and Barbano, 2000).

In this paper, we analyse the active ground deformation of the Hyblean plateau by means of a GPS network, since it can provide data on the local kinematics of the area and on the role played by the local tectonic structures. 


\section{Geodetic networks and surveys}

Just after the December 13, 1990 earthquake, a first GPS surveys was performed in 1991 in the epicentral area, across the Scordia-Lentini graben, with the aim to detect the near field deformation related with this tectonic structure (Achilli et al., 1995). The surveyed network consisted of eight stations with an average grid of a few kilometres, monumented by stainless steel nails located on the massive outcropping units. The GPS network partially included the already existing local trilateration network (surveyed by the Electromagnetic Distance Measurement technique) installed by the International Institute of Volcanology (IIV) of Catania in the same period for similar aims (Achilli et al., 1991) and the IGMI levelling route. Unfortunately, the first GPS campaign partially failed due to electromagnetic noise at GPS frequencies and receiver malfunctions, that prevented a detailed analysis of the data.

After 1991 the GPS network was extended and currently comprises 50 stations, including the older EDM and GPS benchmarks (fig. 2). The new geodetic monuments consist in iron and concrete pillars on top of which a screw allows the GPS antenna to be directly installed (fig. 3). This installation allows instrumentation set-up errors to be avoided. In 1998 and 2000, two GPS surveys were carried out and 26 stations of the northern part of network were occupied (table I). The network is located between the town of Syracuse and Catania and extends from the Ionian coastline to the central Hyblean plateau (fig. 2). It was designed with an average grid of

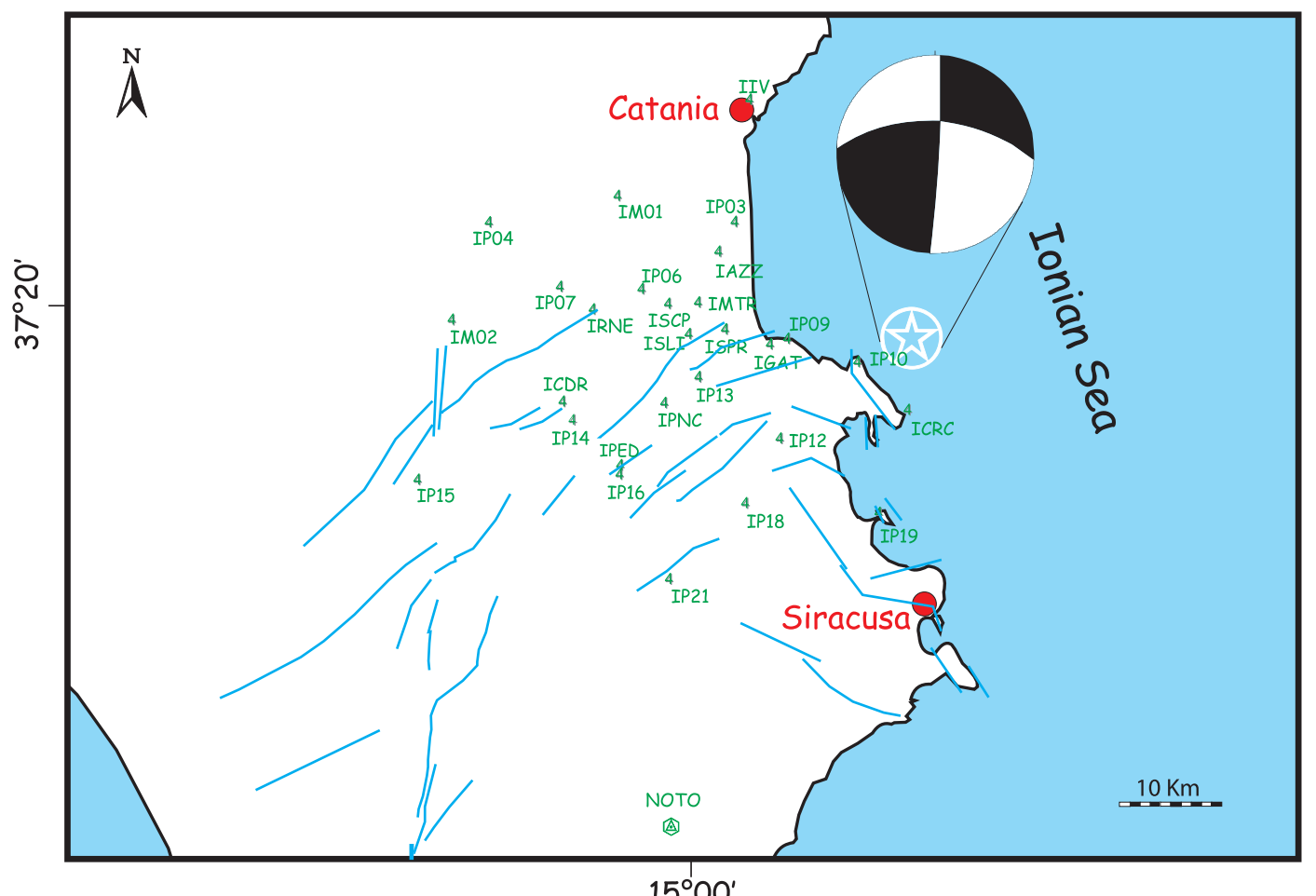

Fig. 2. The Hyblean GPS network. The GPS stations, the main tectonic lineaments of the plateau, the location of the 1990 earthquake and its focal mechanism (star and balloon) (from Amato et al., 1995) are reported in the map. 


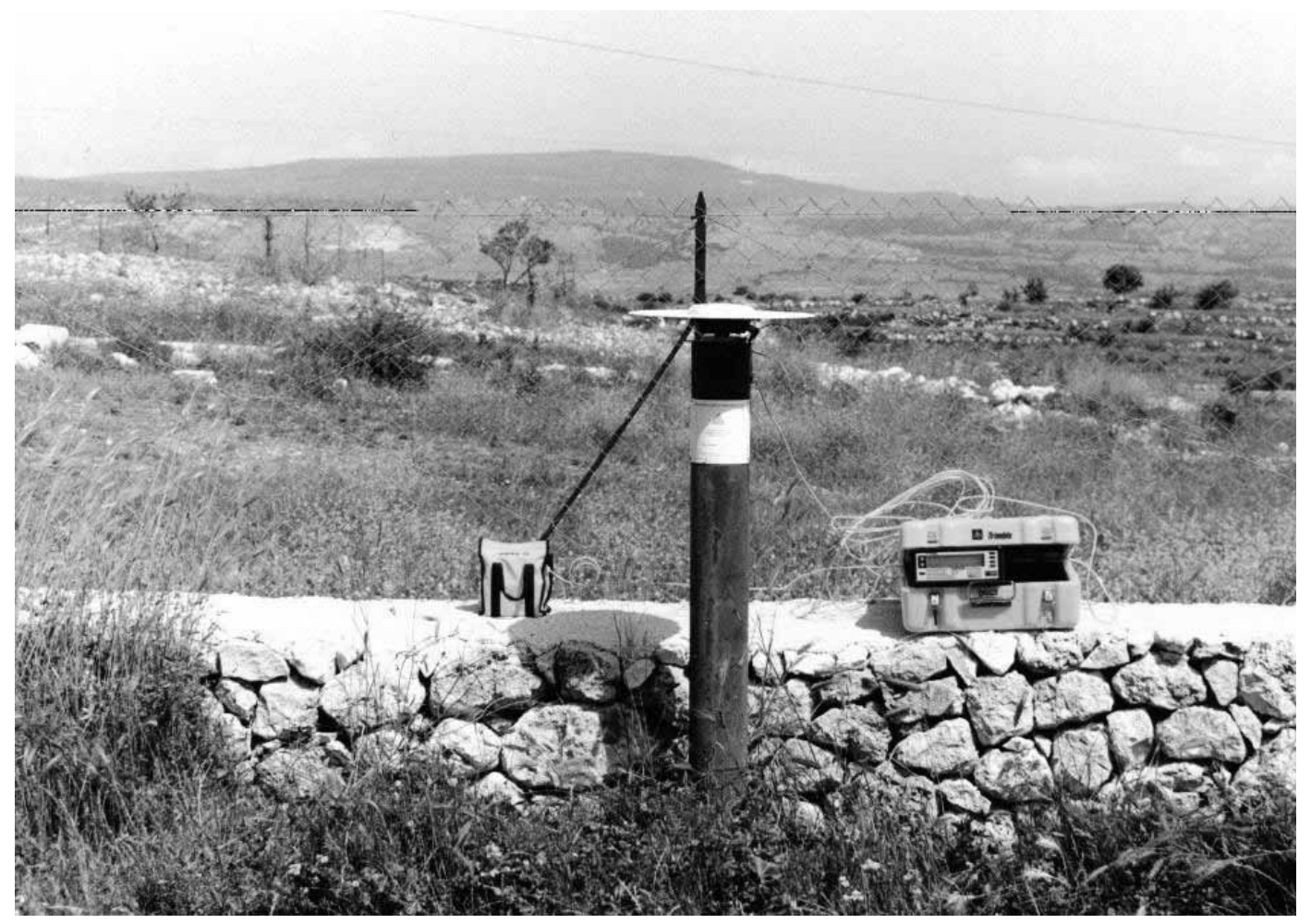

Fig. 3. Typical station of the Hyblean GPS network (IP21 pillar).

Table I. General features of the 1998 and 2000 surveys.

\begin{tabular}{ccccccccc}
\hline \hline $\begin{array}{c}\text { Survey } \\
\text { epoch }\end{array}$ & Start & End & Sessions & $\begin{array}{c}\text { Obs } \\
\text { time }\end{array}$ & $\begin{array}{c}\text { Local } \\
\text { stations }\end{array}$ & $\begin{array}{c}\text { IGS } \\
\text { stations }\end{array}$ & $\begin{array}{c}\text { Local } \\
\text { permanent } \\
\text { stations }\end{array}$ & $\begin{array}{c}\text { Discarded } \\
\text { baselines }\end{array}$ \\
\hline 1998 & April 20th & April 24th & 5 & $6-8 \mathrm{~h}$ & 26 & 3 & 1 & $5 \%$ \\
2000 & May 8th & May 12th & 5 & $6-8 \mathrm{~h}$ & 26 & 3 & 4 & $3 \%$ \\
\hline
\end{tabular}

about $10 \mathrm{~km}$ to constrain both the local seismic and aseismic crustal deformations related to the present tectonic activity.

During the April 1998 survey, 16 dual frequency Trimble GPS receivers were used (models 4000 SSi and SSE), equipped with Choke Ring or Compact L1/L2 with ground plane antennas. A further dual frequency Novatel Propak II receiver, equipped with a model 503 Choke
Ring L1/L2 antenna, was installed at the northernmost station of the network (IIV station). Due to the short baselines, which do not require long observation sessions to obtain an affordable data set for geophysical applications, survey sessions were planned spanning from 6 to $8 \mathrm{~h}$ for the rover receivers.

The three IGS stations of Noto (NOTO), Matera (MATE) and Cagliari (CAGL), together 
Table II. Schedule of daily sessions of the 1998 survey.

\begin{tabular}{c|c|c|c|c|c|c|c|c}
\hline \hline \multicolumn{1}{c}{1998 GPS survey daily sessions } \\
\hline \multirow{2}{*}{ April 20 } & IPED & IRNE & IAZZ & ISPR & IP13 & ISLI & IP03 & IM01 \\
\cline { 2 - 9 } & IP04 & IM02 & IP07 & IP06 & ISCP & ICDR & IPNC & IIV \\
\hline \multirow{2}{*}{ April 21 } & IPED & IRNE & ICRC & ISPR & IP13 & IGAT & IP18 & IP21 \\
\cline { 2 - 9 } & IP19 & IM02 & IP12 & IP06 & IMTR & IPNC & ISCP & \\
\hline \multirow{2}{*}{ April 22 } & IPED & IAZZ & ICRC & ISPR & IGAT & ISLI & IP03 & IP19 \\
\cline { 2 - 9 } & IP10 & IP12 & IP07 & IP09 & ISCP & IP06 & IMTR & IIV \\
\hline \multirow{2}{*}{ April 23 } & IRNE & ICRC & IAZZ & ISLI & IGAT & IP13 & IM01 & ICDR \\
\cline { 2 - 9 } & IP04 & IP21 & IP18 & IP09 & IMTR & IP10 & IIV & \\
\hline \multirow{2}{*}{ April 24 } & IP03 & IP19 & IP21 & IM02 & IP07 & IIV & & \\
\cline { 2 - 8 } & & & & & & & & \\
\hline
\end{tabular}

Table III. Schedule of daily sessions of the 2000 survey. The higher redundancy in station occupations, with respect to the 1998 survey, is due to the higher number of available GPS receivers.

\begin{tabular}{|c|c|c|c|c|c|c|c|c|c|c|}
\hline \multicolumn{11}{|c|}{2000 GPS survey daily sessions } \\
\hline \multirow{2}{*}{ May 8} & $I I V$ & IP18 & IP15 & IP07 & IP12 & ISCP & ICDR & IMTR & IPNC & IM01 \\
\hline & IAZZ & ICRC & IRNE & ISLI & IGAT & IP09 & IP10 & IM02 & IP13 & IP14 \\
\hline \multirow{2}{*}{ May 9} & $I I V$ & IP18 & $I P 15$ & IP07 & IP06 & IP13 & ICDR & IMTR & IPNC & IP12 \\
\hline & IAZZ & ICRC & IRNE & ISLI & IGAT & IP04 & IP19 & IP16 & IP21 & IP14 \\
\hline \multirow{2}{*}{ May 10} & $I I V$ & $I 18$ & IP15 & IP07 & IP09 & ISCP & ICDR & IMTR & IP03 & IM02 \\
\hline & IAZZ & ICRC & IRNE & ISLI & IGAT & IP04 & IP19 & IM01 & IP21 & IP16 \\
\hline \multirow{2}{*}{ May 11} & $I I V$ & IP18 & $I P 15$ & IP07 & IP14 & ISCP & IP06 & IP03 & IM02 & IP10 \\
\hline & IP12 & IP13 & IP04 & IP19 & IM01 & IP21 & IP16 & & & \\
\hline \multirow{2}{*}{ May 12} & $I I V$ & IP18 & $I P 15$ & IP07 & IM02 & IP03 & IP06 & IP09 & IP10 & \\
\hline & & & & & & & & & & \\
\hline
\end{tabular}

with Catania (IIV), observed a continuous $30 \mathrm{~s}$ sampling rate throughout the campaign. During each survey session, about 15 stations were measured and each station was occupied at least twice to provide a robust daily data set (table II).

During May 2000, the GPS survey was repeated (table III). In order to avoid systematic errors we used the same Trimble instruments as the previous surveys. Five survey sessions were planned during the week-long campaign, by measuring up to 20 stations each day with a $6 \mathrm{~h}$ observation window at $30 \mathrm{~s}$ sampling rate. Three stations were equipped and planned to acquire data continuously, together with Catania (IIV) and the three IGS stations used in the previous surveys. Although this campaign was planned to occupy each station at least twice, thanks to the high number of available instruments, three measurements were carried out for almost all benchmarks of the network (table III), achieving a higher redundancy with respect to the previous survey.

\section{GPS data processing and analysis of the results}

GPS data collected during 1998 and 2000 surveys were processed using the Trimble Geo- 
matics Office software, version 1.5 (Trimble, 2001). Precise ephemerides produced by the IGS were used during processing to achieve a higher accuracy during the baselines computation (Beutler et al., 1990). Data from NOTO, MATE and CAGL IGS stations, belonging to the ITRF network, were added to the processing, in order to connect the Hyblean network to the international frame.

GPS data were processed using both L1 and L2 frequencies. The Iono free linear combination L3 was adopted to avoid the bias produced by the ionosphere delay on the GPS signal propagation. A threshold of $10 \mathrm{~km}$ was introduced into the processing for the L3 application, taking into account that for short baselines the noise introduced by the L3 combination may be of the same order of the ionospheric bias. A summary of the baselines processing relevant to each survey is reported in table I. This table shows a decrease in the percentage of discarded
Table IV. Transformation parameters for 1998 and 2000 network adjustments.

\begin{tabular}{c|c|c}
\hline \hline $\begin{array}{c}\text { Similarity } \\
\text { transformation } \\
\text { parameters }\end{array}$ & 1998 & 2000 \\
\hline $\begin{array}{c}\text { Translation along X } \\
(\mathrm{m})\end{array}$ & $\begin{array}{c}-0.042 \\
\pm 0.006\end{array}$ & $\begin{array}{c}0.275 \\
\pm 0.001\end{array}$ \\
\hline $\begin{array}{c}\text { Translation along y } \\
(\mathrm{m})\end{array}$ & -0.033 & 0.164 \\
\pm 0.006 & \pm 0.001 \\
\hline Translation along H & 0.006 & -0.136 \\
$(\mathrm{~m})$ & \pm 0.008 & \pm 0.009 \\
\hline Azimuth rotation & -0.0001 & -0.0082 \\
(arc second) & \pm 0.0005 & \pm 0.0004 \\
\hline Deflection in lat. & -0.0182 & -0.0178 \\
(arc second) & \pm 0.042 & \pm 0.0027 \\
\hline Deflection in long. & 0.0167 & 0.126 \\
(arc second) & \pm 0.024 & \pm 0.0014 \\
\hline Network scale & -0.069 & -0.01 \\
(mm/km) & \pm 0.003 & \pm 0.000 \\
\hline \multicolumn{2}{|c}{} \\
\hline
\end{tabular}

Table V. Coordinate variations between 1998 (epoch 1998) and 2000 (epoch 2000). The average formal errors are about $3 \mathrm{~mm}$ for the horizontal component and about $4-5 \mathrm{~mm}$ for the vertical one.

\begin{tabular}{|c|c|c|c|c|c|c|}
\hline Station & Delta Lat (m) & DLat err (m) & Delta Lon (m) & DLon err (m) & Delta H (m) & DH err $(m)$ \\
\hline IAZZ & 0.041 & 0.001 & 0.040 & 0.001 & 0.011 & 0.004 \\
\hline ICDR & 0.039 & 0.002 & 0.044 & 0.002 & -0.007 & 0.004 \\
\hline ICRC & 0.040 & 0.001 & 0.031 & 0.001 & 0.015 & 0.004 \\
\hline IGAT & 0.040 & 0.001 & 0.040 & 0.001 & 0.012 & 0.004 \\
\hline IIV & 0.034 & 0.001 & 0.032 & 0.001 & -0.092 & 0.004 \\
\hline IM01 & 0.034 & 0.002 & 0.040 & 0.002 & 0.021 & 0.004 \\
\hline IM02 & 0.038 & 0.001 & 0.049 & 0.001 & 0.014 & 0.004 \\
\hline IMTR & 0.033 & 0.001 & 0.027 & 0.001 & -0.032 & 0.004 \\
\hline IP03 & 0.042 & 0.001 & 0.031 & 0.001 & -0.001 & 0.004 \\
\hline IP04 & 0.022 & 0.002 & 0.052 & 0.002 & -0.034 & 0.004 \\
\hline IP06 & 0.046 & 0.002 & 0.044 & 0.001 & 0.009 & 0.004 \\
\hline IP07 & 0.039 & 0.002 & 0.043 & 0.001 & 0.010 & 0.004 \\
\hline IP09 & 0.039 & 0.002 & 0.040 & 0.002 & -0.002 & 0.004 \\
\hline IP10 & 0.039 & 0.002 & 0.046 & 0.002 & 0.006 & 0.004 \\
\hline IP12 & 0.041 & 0.002 & 0.043 & 0.002 & 0.013 & 0.004 \\
\hline IP13 & 0.035 & 0.001 & 0.041 & 0.001 & 0.011 & 0.004 \\
\hline IP16 & 0.051 & 0.003 & 0.043 & 0.003 & 0.020 & 0.007 \\
\hline IP18 & 0.048 & 0.002 & 0.040 & 0.002 & 0.018 & 0.004 \\
\hline IP19 & 0.054 & 0.001 & 0.048 & 0.001 & 0.007 & 0.004 \\
\hline IP21 & 0.047 & 0.001 & 0.044 & 0.001 & -0.014 & 0.004 \\
\hline IPNC & 0.043 & 0.003 & 0.043 & 0.003 & -0.009 & 0.004 \\
\hline IRNE & 0.037 & 0.002 & 0.043 & 0.002 & -0.025 & 0.006 \\
\hline ISCP & 0.040 & 0.002 & 0.042 & 0.002 & 0.014 & 0.004 \\
\hline ISLI & 0.044 & 0.002 & 0.040 & 0.002 & 0.013 & 0.004 \\
\hline CAGL & 0.026 & Fixed & 0.044 & Fixed & 0.001 & Fixed \\
\hline MATE & 0.038 & Fixed & 0.047 & Fixed & -0.002 & Fixed \\
\hline NOTO & 0.036 & Fixed & 0.043 & Fixed & -0.003 & Fixed \\
\hline
\end{tabular}


solutions for the second campaign; this is mainly due to the presence of a higher number of stations for which a $24 \mathrm{~h}$ set of data was suitable. This allowed us to recover some bad solutions, by reducing, changing and moving the processed time window, in order to use the best available data set.

After processing the baselines, the networks were adjusted without introducing constraints, to verify the internal consistency of the data set and to estimate the positioning errors at each station. Following this first step in the adjustment computation, once stable network solutions were obtained, the coordinates of the three IGS stations were fixed. Reference station coordinates were derived from the ITRF2000 solution, using the velocity model produced for each station by the IGS.

The 1998 and 2000 campaigns were adjusted by fixing the coordinates on the NOTO, MATE and CAGL IGS stations calculated at April 1998
Table VI. Transformation parameters for 1998 network adjustment, fixed at epoch 2000.

\begin{tabular}{c|c}
\hline \hline $\begin{array}{c}\text { Similarity } \\
\text { transformation } \\
\text { parameters }\end{array}$ & $\begin{array}{c}1998 \text { (fixed at } \\
\text { apoch 2000) }\end{array}$ \\
\hline $\begin{array}{c}\text { Translation along X } \\
\text { (m) }\end{array}$ & 0.001 \\
Translation along y & 0.006 \\
(m) & 0.002 \\
Translation along H & \pm 0.006 \\
\hline Azimuth rotation & 0.001 \\
(arc second) & \pm 0.008 \\
\hline Deflection in lat. & -0.0009 \\
(arc second) & \pm 0.0005 \\
\hline Deflection in long. & -0.0123 \\
(arc second) & \pm 0.026 \\
\hline Network scale & 0.0134 \\
(mm/km) & \pm 0.016 \\
\hline
\end{tabular}

Table VII. Coordinate variations between 1998 and 2000, with both networks fixed at epoch 2000. The mean formal error is about $3 \mathrm{~mm}$ for the horizontal component and $4-5 \mathrm{~mm}$ for the vertical one.

\begin{tabular}{cccccrc}
\hline \hline Station & Delta Lat $(\mathrm{m})$ & DLat err $(\mathrm{m})$ & Delta Lon $(\mathrm{m})$ & DLon err $(\mathrm{m})$ & Delta H $(\mathrm{m})$ & DH err $(\mathrm{m})$ \\
\hline IAZZ & 0.006 & 0.001 & -0.003 & 0.001 & 0.017 & 0.004 \\
ICDR & 0.004 & 0.002 & 0.000 & 0.002 & -0.003 & 0.004 \\
ICRC & 0.005 & 0.001 & -0.012 & 0.001 & 0.020 & 0.004 \\
IGAT & 0.005 & 0.001 & -0.004 & 0.001 & 0.016 & 0.004 \\
IIV & -0.001 & 0.001 & -0.011 & 0.001 & -0.086 & 0.004 \\
IM01 & -0.001 & 0.002 & -0.003 & 0.002 & 0.026 & 0.004 \\
IM02 & 0.003 & 0.001 & 0.006 & 0.001 & 0.020 & 0.003 \\
IMTR & -0.002 & 0.001 & -0.016 & 0.001 & -0.027 & 0.004 \\
IP03 & 0.007 & 0.001 & -0.012 & 0.001 & 0.004 & 0.004 \\
IP04 & -0.012 & 0.002 & 0.009 & 0.002 & -0.030 & 0.004 \\
IP06 & 0.011 & 0.001 & 0.001 & 0.001 & 0.014 & 0.004 \\
IP07 & 0.004 & 0.001 & 0.000 & 0.001 & 0.016 & 0.004 \\
IP09 & 0.004 & 0.002 & -0.004 & 0.002 & 0.003 & 0.004 \\
IP10 & 0.004 & 0.002 & 0.003 & 0.002 & 0.010 & 0.004 \\
IP12 & 0.006 & 0.002 & -0.001 & 0.002 & 0.018 & 0.004 \\
IP13 & 0.000 & 0.001 & -0.002 & 0.001 & 0.016 & 0.004 \\
IP16 & 0.015 & 0.003 & 0.000 & 0.003 & 0.026 & 0.007 \\
IP18 & 0.012 & 0.002 & -0.003 & 0.002 & 0.023 & 0.004 \\
IP19 & 0.019 & 0.001 & 0.005 & 0.001 & 0.012 & 0.004 \\
IP21 & 0.011 & 0.001 & 0.001 & 0.001 & -0.009 & 0.004 \\
IPNC & 0.008 & 0.003 & 0.000 & 0.003 & -0.004 & 0.004 \\
IRNE & 0.002 & 0.002 & 0.000 & 0.002 & -0.020 & 0.006 \\
ISCP & 0.005 & 0.002 & -0.002 & 0.002 & 0.018 & 0.004 \\
ISLI & 0.009 & 0.002 & -0.003 & 0.002 & 0.018 & 0.004 \\
CAGL & 0.000 & Fixed & 0.000 & Fixed & 0.000 & Fixed \\
MATE & 0.000 & Fixed & 0.000 & Fixed & 0.000 & Fixed \\
NOTO & 0.000 & Fixed & 0.000 & Fixed & 0.000 & Fixed \\
\hline
\end{tabular}


and May 2000 epochs, obtaining average formal errors of about $2 \mathrm{~mm}$ for the $\mathrm{N}$, E components and of about $3 \mathrm{~mm}$ for the Up component, at 95\% confidence level. Table IV lists the transformation parameters for the 1998 and 2000 constrained adjustment.

The coordinate comparison between the two campaigns shows horizontal displacements up to $54 \pm 3 \mathrm{~mm}$, with a northeast trend at all stations (table V). A similar displacement is shown by the IGS NOTO, MATE and CAGL stations, whose motion is imposed by the velocity model calculated by the IGS.

The vertical component, although less accurate than the horizontal components, displays weak motion. The apparent subsidence measured at IIV station is likely due to a wrong modelling of the GPS antenna offset used in the 1998 survey during the data processing, that probably gives a false height value for that epoch.

To estimate the internal deformation of the area at local scale, a further adjustment was made for the 1998 network. The three IGS reference stations were fixed to the same co-ordinates used to adjust the 2000 network, obtaining a common reference frame for 1998 and 2000 surveys (epoch May 2000). Table VI lists the transformation parameters for the 1998 adjustment constrained to epoch May 2000. The quality of the results of this adjustment are not different to the previous ones. The coordinate comparison between the two epochs referred to the same local frame (table VII) shows displacements within $20 \mathrm{~mm}$ for the $\mathrm{N}$ component, $16 \mathrm{~mm}$ for the E component

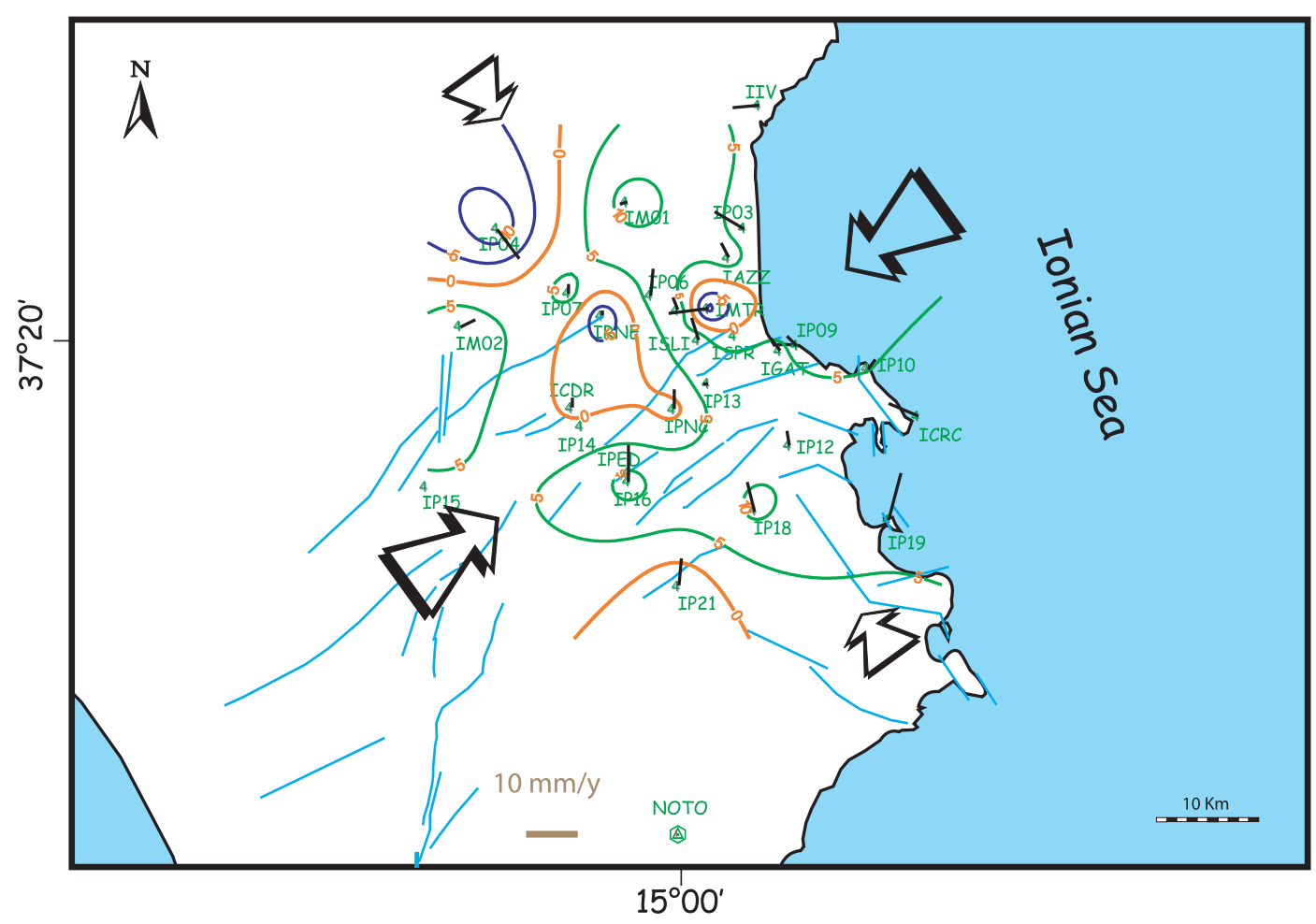

Fig. 4. Horizontal (vectors) and vertical (contours) velocities at the GPS stations (mm/yr) between 1998 and 2000 computed by fixing the IGS stations co-ordinates at epoch 2000.4 . The contour interval is $5 \mathrm{~mm} / \mathrm{yr}$. Large arrows indicate the maximum and minimum shortening strain axes. 
and $30 \mathrm{~mm}$ for the Up component; in this analysis IIV station was excluded due to problems with the antenna modeling during 1998 survey.

\section{Discussion and conclusions}

To analyse the internal deformation of the Hyblean plateau, we compared the GPS data set collected in two different campaigns performed in 1998 and 2000, computed in the same reference frame (fig. 4). It is remarkable that the velocity vectors (fig. 4), suggests a non uniform deformation for the whole network. A quite uniform northward motion trend is evident on the southern part of the network, whereas the northernmost stations show a more scattered orientation of velocity vectors.

The northward motion of the southern part of the network implies an extension zone between this area and the NOTO station, which was considered fixed. Inside the network, the velocities decrease from the southern to the northern stations, suggesting a crustal shortening while approaching the thrust of the Gela nappe (fig. 5a)

The horizontal strain tensor of the whole network was computed using the ellipsoidal distances, to obtain an overview of its areal deformation. The results of the computation (table VIII) show a negative value of the dilatation of the network with a maximum shor-
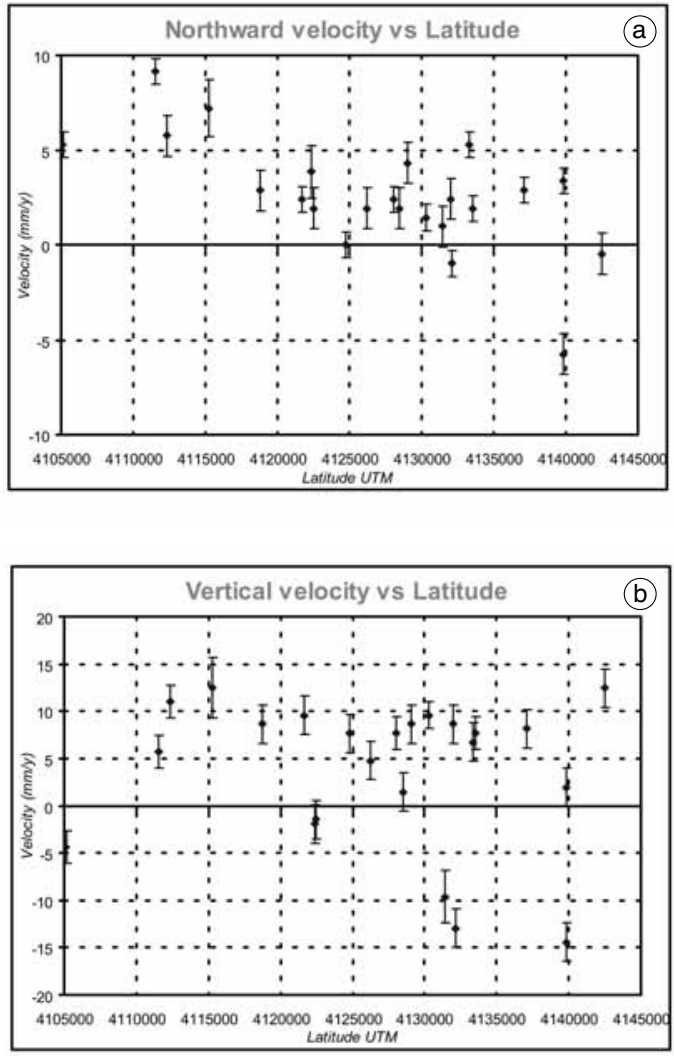

Fig. 5a,b. a) Northward component of velocities versus latitude; b) vertical component of velocities versus latitude.

Table VIII. Overall strain field computed for the geodetic network. The areal dilatation is the sum of the north and east components. Negative values represent shortening. The network displays a general contraction with a maximum shortening axis trending NE-SW.

\begin{tabular}{lcc}
\hline \hline & Value & Error \\
\hline Strain components & & \\
East strain component & $-0.33 \mathrm{ppm}$ & $0.045 \mathrm{ppm}$ \\
Shear strain component & $-0.12 \mathrm{ppm}$ & $0.0804 \mathrm{ppm}$ \\
North strain component & $-0.29 \mathrm{ppm}$ & $0.0485 \mathrm{ppm}$ \\
& & \\
Principal axes & & \\
Min shortening & $-0.25 \mathrm{ppm}$ & $0.0485 \mathrm{ppm}$ \\
Max shortening & $-0.38 \mathrm{ppm}$ & $0.045 \mathrm{ppm}$ \\
Min shortening azimuth & $-35.9484^{\circ}$ & $20.2543^{\circ}$ \\
Max shortening azimuth & $54.05164^{\circ}$ & $20.2543^{\circ}$ \\
Areal dilatation & $-0.62 \mathrm{ppm}$ & $0.0935 \mathrm{ppm}$ \\
\hline
\end{tabular}


tening axis trending NE-SW (arrows in fig. 4). Deformation values are very weak (less than $1 \mathrm{ppm})$, and the overall compressional regime largely depends on the displacements affecting the northernmost stations, located on the foredeep. A detailed analysis of the strain distribution in the study area is useful to investigate the behaviour of the different sectors of the plateau as, for instance, the Scordia-Lentini graben area.

Moreover, although the data refer only to a two year time span, a vertical deformation affects the northern side of the network, whereas a weak uniform uplift occurs in its southern part (fig. 4 and 5b). The three stations IP04, IRNE and IMTR, located on the northern part of the network are affected by subsidence.

The IP04 station, which shows a vertical velocity of $-15 \pm 2 \mathrm{~mm} / \mathrm{yr}$ and a horizontal SE displacement (fig. 4), lies on the north-western end of the network, along the Gela-Catania foredeep (see fig. 1). Since this pillar lies on the Catania alluvial plain, it is not yet clear if this motion is due to the regional kinematics, like the foredeep subsidence, or to soil compaction.

IMTR and IRNE stations, located on the massive outcropping units of the Scordia-Lentini graben, are subsiding at rates of $-13 \pm 2$ and $-10 \pm 3 \mathrm{~mm} / \mathrm{yr}$, respectively. Although their behaviour can be due to a general subsidence of this tectonic structure, the other stations of the GPS network located on the same tectonic structure do not show comparable subsidence. Furthermore, IRNE station does not show horizontal motion, whereas IMTR displays a clear westward displacement that is quite different from the surrounding stations.

In any case, the detected vertical deformation is near the height resolution of GPS measurements, thus longer time span between surveys is required to obtain more definitive results.

\section{Acknowledgements}

We thank Massimo Bacchetti, Giuseppe Capone, Sergio Del Mese, Giuseppe Di Grazia, Cristiano Guidi and Andrea Ursino for their helpful participation in field surveys.

This work has been partially funded by Italian Space Agency.

\section{REFERENCES}

ACHILli, V., M. ANZIDEI, P. BALDI, R. VelarditA and F. BROCCIO (1991): La rete geodetica GPS della Sicilia Sud orientale, in Contributi allo Studio del Terremoto della Sicilia Orientale del 13 dicembre 1990, Istituto Nazionale di Geofisica, publication n. 537, 151-162.

ACHILli, V., M. ANZIDEI, P. BAldi, F. BRoccio and R. VELARDita (1995): The Southeastern Sicily GPS network, Ann. Geofis., 38 (2), 301-308.

AdAM, J., C.D. Reuther, M. Grasso and L. Torelli (2000): Active fault kinematics and crustal stresses along the Ionian margin of Southeastern Sicily, Tectonophysics, 326, 217-239.

Amato, A., R. Azzara, A. Basili, C. Chiarabba, M. Cocco, M. Di Bona and G. SelvagGi (1995): Main shock and aftershocks of the December 13, 1990, Eastern Sicily earthquake, Ann. Geofis., 38 (2), 255-266.

AzZARO, R. and M.S. BArbano (2000): Analysis of the seismicity of Southeastern Sicily: a proposed tectonic interpretation, Ann. Geofis., 43 (1), 171-188.

Ben Avraham, Z. and M. Grasso (1991): Crustal structure variations and transcurrent faulting at the eastern and western margins of the Eastern Mediterranean, Tectonophysics, 196, 269-277.

Ben Avraham, Z., M. Boccaletti, G. Cello, M. Grasso, F. Lentini, L. TORELli and L. TORTOTICI (1990): Principali domini strutturali originatisi dalla collisione Neogenico-Quaternaria nel Mediterraneo centrale, Mem. Soc. Geol. It., 45, 453-462.

Ben Avraham, Z., V. Lyakhovskyy and M. Grasso (1995): Simulation of collision zone segmentation in the Central Mediterranean, Tectonophysics, 243, 57-68.

Beutler, G., W. Gurtner, M. Rotacher, U. WiLD and E. FREI (1990): Relative static positioning with the Global Positioning System: basic technical considerations, in Global Positioning System: an Overview, edited by Y. BOCK and N. LEPPARD (Springer Verlag, Berlin), 1-23.

Giardini, D., B. PAlombo and N.A. PINO (1995): Longperiod modelling of MEDNET waveforms for the December 13, 1990 Eastern Sicily earthquake, Ann. Geofis., 38 (2), 267-282.

Grasso, M., B. Philips, C.D. Reuther, P. Garofalo, R. Stamilla, G. Anfuso, G. DonZella and G. Cultrone (2000): Pliocene-Pleistocene tectonics on the western margin of the Hyblean plateau and the Vittoria Plain (SE Sicily), Mem. Soc. Geol. It., 55, 35-44.

Mulargia, F., V. ACHILli, F. BROCCIO and P. BALDI (1991): Is a destructive earthquake imminent in Southeastern Sicily? Tectonophysics, 188, 399-402.

SCARFi, L., H. LANGER, G. Di GRAZIA, A. URSINO and S. GrESTA (2001): Analysis of two microearthquake swarms in Southeastern Sicily: evidence for active faults? Ann. Geofis., 44 (4), 671-686.

Trimble NAVIGATION Limited (2001): Trimble Geomatic Office Vers. 1.5 (U.S.A.).

(received June 11, 2002; accepted October 3, 2002) 